\title{
THE POTENTIAL IRRA TARGET SITES FOR THE RIBOSOMAL PROTEIN L10 FOUND IN STREPTOMYCES GRISEUS AND S. COELICOLOR GIVE EVIDENCE FOR THE AUTOGENOUS REGULATION OF EXPRESSION OF THE rPIJL GENES
}

\begin{abstract}
On the basis of structural simllarity between the $m$-and $r$ RNA binding sites which underlies the molecular mechanism of the autogenous control of expression of the rolJL genes, mediated in prokaryotic organisms by ribosomal protein L10, we attempted to find the potential $m R N A$ target sites in $S$. griseus and $S$, coelicolor. The potential targets found in both species of Streptomyces are of highly conserved structure and contain elements similar with the LIO binding domain of the 23S RNA. Compared to the L10. mRNA targets of Enterobacteria, Thermotoga maritima and Synechocystis, the target sites of Streptomyces contain a larger number of conserved and specific structural elements, similar in both analyzed species. Comparison of the structural organization of the \&Streptomyces and eEnterobacterials types of the L10 mRNA targets with the structure of the L1O binding domain in the $23 S$ RNA reveals that the elements, conserved in all the mentioned targets, are located in the ssA and $d s A$ regions. The structure of the potential $L 10 \mathrm{mRNA}$ target sites, which mimic the $r R N A$ target of the regulatory ribosomal protein L1O, gives evidence for the autogenous L1O-mediated control of expression of the rplJL genes in Streptomyces.
\end{abstract}

The expression of genes in the majority of ribosomal protein operons in prokaryotic organisms is regulated autogenously at the translational level [1]. This mode control is achieved due to the possibility of the regulatory ribosomal proteins, encoded by the mRNA of the controlled operons, to bind in a competitive manner the target sites in the $m$ - and rRNA. The structural organization of these sites is highly homologous. In case of the $r p l J L$ operon, whose genes are regulated by $r$-protein $L I O$ (or its $1: 4$ complex with L12) [2] we observed the possibility for heterologous translational feedback control in Enterobacteria $[3,4]$, provided by the highly conserved structure of both, the regulatory $L 10$ proteins [5] and their mRNA target sites [6]. Of particular interest is the fact, that in case of the L1O target sites, whose structure is proved for Enterobacteria [6] and putative - for Synechocystis PCC 6803 [7] and Thermotoga maritima ([8]; Paton and Zhyvoloup, unpublished data), the degree of homology between the mRNA target sites is higher than between the respective rRNA targets. Moreover, additional structural similarity between the $m-$ and rRNA targets of the $L 10$ protein is characteristic of Enterobacteria, Synechocystis ani Thermotoga. This makes it reasonable to assume that the $L 10$-RNA interaction, which mediates the autogenous regulation of the rplJL genes expression is species- and organism-specific. Existence of the \&specifying» complementary structural elements, is to be found in both, the regulatory proteins [9] and their mRNA binding sites $[6-8]$. The latter might be of importance to provide the efficient recognition and tight binding the $L 1 O$ protein to the mRNA, which in the case of the rRNA target would be achieved via the cooperative binding of the neighbouring r-proteins. Comparison of the L1O binding regions in the rplJ leaders of seven enterobacterial species [6] reveals that the AA1571-1572 (ennumeration as in $E$. coli $[10,11])$, whose interaction with the $L 10$ protein had been proven by chemical analysis [11], are con-

(C) Eugenia B. Paton, 1996 
served. The conservation of AA1571-1572 in the potential L1O mRNA. targets of Synechocystis and Thermotoga (see Fig.) allows an assumption that AA1571-1572 in all of these mRNA targets, are involved in binding to a complementary conserved structural elements of the regulatory protein $L 10$. It is notable that the structural homologs of AA15711572 in the $23 S$ rRNA belong to binding domain of r-protein $L I I$ [12]. We reasoned that in other prokaryotic organisms whose $r p l J L$ genes were feedback-regulated by $L 1 O$, the regulatory $L 10$-mRNA interaction might also involve additional structural elements, however, possibly different from AA1571-1572. The present paper is devoted to the analysis of the rplJ leader region of $S$. griseus and $S$, coelicolor, whose nucleotide sequence was recently determined $[13,14]$. The special attempt was made to find the potential $L 10$ binding sites and, if it were the case, to compare their structural organization in the both species to the structure of the so far determined mRNA targets of L1O. The following logic underlied the search for the potential $L 10$ mRNA target sites.

The mRNA target site of the regulatory protein $L 10$ is to be homologous to the rRNA target in as much as to provide the competitive binding of the $L 10$ protein. In all the cases documented so far $[2,6-8,11]$ the mRNA target sites for the $L 1 O$ protein are located in the untranslated rplJ leader region. In both species of Streptomyces, the untranslated leader precedes the start of the L1O cistron. We further analysed the structural homology of the rplJ leaders of Streptomyces with the L10 mRNA target sites of Enterobacteria, Synechocystis PCC 6803 and Thermotoga maritima, as well as with the $L 10$ binding domain of the $23 S$ RNA of Streptomyces ambofaciens (see Fig., A). The alignment of the nucleotide sequences was made using the ALIGN program (PCGENE software package). The secondary structure prediction was carried out using the RNAFOLD program (PCGENE). Motives of primary structure identical to the Synechocystis and the Enterobacterial consenstrs LIO mRNA target sites were found in the rplJ leaders of both species of Streptomyces. Further on, the secondary structure of the potential mRNA LiO binding sites was calculated (results shown in Figure).

One can notice the pronounced similarity of structure of both $S$. griseus and $S$. coelicolor putative $L 1 O$ binding sites with the consensus $L 1 O$ binding domain of the 23S RNA [12]. The most striking similarity with the 23S RNA is accounted for by the common general organization, where of particular interest is the presence in the mRNA targets of Sireptomyces of the two (dsB and dsD) double-stranded regions, rather than a single (dsB) region, which is typical for all of the so far known L1O mRNA binding sites. The structural organization of the potential L1O binding sites is highly similar in $S$. griseus and $S$. coelicolor. The singlestranded region $C$ ( $\mathrm{sSC}$ ) is different from the relevant region of the $23 S$ RNA, as a well as from the other prokaryotic mRNA targets. The latter would contain the typical conserved UUAA motif (see Fig., $B$ ). It is noteworthy that the dsC regions are conserved in both types of mRNA targets «enterobacterial» and «Streptomyces» like. However identical within the two types of targets are only the two pairs, G-C and $C-G$ in the dsC region. The highest degree of homology of the mRNA targets in $S$. grise$u s$ and $S$. coelicolor is found in the $\mathrm{dsC}$, ss A and sdA regions (see Fig., $B$ ). The structure in dsC region is completely conserved, except the internal loop, which in $S$. griseus is formed of the $\mathrm{U}, \mathrm{U}$, while in $S$. coelicolor - of $U, C$. The bulged nucleotides are typical structural elements for the protein-nucleic acid interaction. Therefore, we should not exclude the possible species-specifying role of the loop in the dsC region. The $\mathrm{dsB}, \mathrm{dsC}$ and dsD regions in both pro- and eukaryotic $23 \mathrm{~S}$ RNA belong to the $L 11$ binding domain [12], which is interchangable for $E$. coli and yeasts [15]. As already noticed, the mRNA targets of Enterobacteria, $S y$ nechocystis and Thermotoga, although lacking the dSD region, do conta. in the conserved UUAA motif in the dsC (Fig.). Therefore the structural similarity to the $L 11$ binding domain of the $23 \mathrm{~S}$ RNA is present in both 

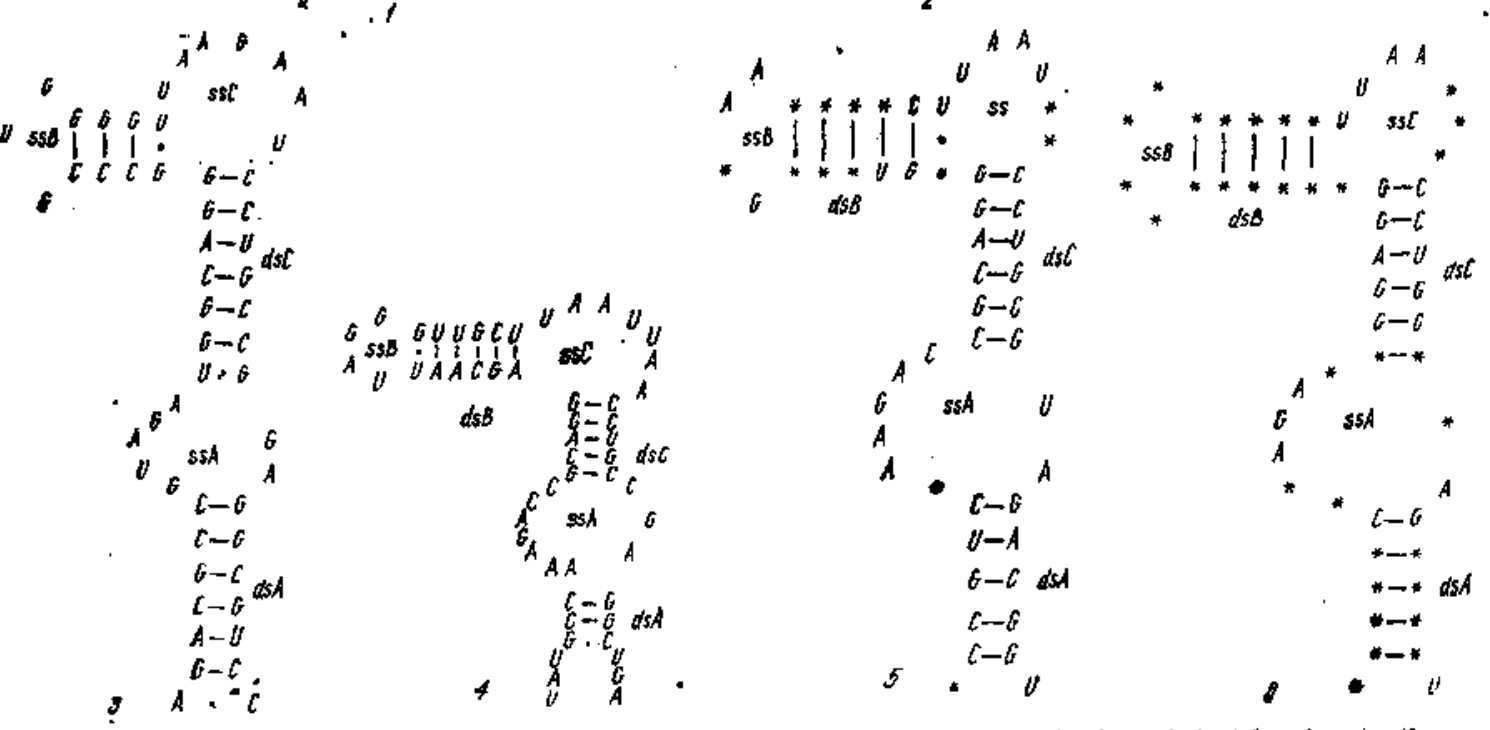

The secondary structure of the $\operatorname{TRNA}(A)$ and mRNA $(B)$ binding sites of the ribosomal protein L10: $A-$ - rRNA target sites $(1-$ the con sensus secondary structure of $L 10$ binding re gion of the 23S rRNA [12]. Capitals tenote nucleotides conserved amongst at least 30 of 31 aligned 23S RNA of eukaryotes, archaebac as purines or pyrimidines. Base-pairs prover by coordinated base changes in all three kingdoms are denoted by lines; 2-- the secondary structure of the L1O binding domain of the $S$. ambolaciens 23S RNA [17]); $B-$ mRNA target sites of $L 10$ ( 1 - the potential L1O target sites of $S$. griseus and $2-S$. coelicolor, lower case letters denote nucleotides conserved in both species: 3 - secondary structure of the potential L10 target site of Thermotoga maritima based on the nucleotide sequence [6] and mRNA secondary structure computation; 4the potential target of the synechocysis PCC 6803 [7]; 5- secondary structure of the consensus enterobacterial mRNA target based on comparisor of the nucleotide sequences $[2,4]$ and secondary structure prediction. Asterisks denote the variable nucleotides; $6-$ secondary structure of the L10 mRNA target, consensus for Enterobacteria, Th. maritima and Synechocystis. Asterisks denote the variable nucleotides. The conserved base pairs are denoted by lines 
types of the mRNA LIO targets («Enterobacterial» and «Streptomyces»). In Streptomyces, however, this similarity is much higher due to the presence of the dsD region and therefore makes it tempting to assume that $L 11$ protein, in addition to $L 10$, might be involved in Streptomyces in the control of expression of the rplJL genes. The functional role of $L I 1$ here might consist in co-regulation of expression of the rplA and the rplJL genes.

The structural elements which comprise the most important similarity between the two types of mRNA targets, the «Enterobacterial» and «Streptomyces» like, are to be found in regions ssA and dsA. The conserved elements in the ssA region are: the AGA motif on the left side and the $A$, adjacent to the first $C-G$ pair of the ds $A$ region, on the right side of region ssA. The $C-G$ pair is the most essential conservation in the dsA region. The formation - of this $C-G$ pair provides the most complete structural similarity between the m- and rRNA targets of L10 [16]. This feature is exploited in the models of the conformational switches of the $r p l J$ leaders of $E$. coli :[2] and the six other species of Enterobacterid [6], as well as those of Thermotoga maritima and Synechocystis (Paton and Zhyvoloup, unpublished) to explain the molecular mechanism of the $L 10$-mediated feedback regulation. The conservation of the C-G pair (ds A) and the adjacent $A$ (ssA) in the putative mRNA target sites of the L1O protein of Streptomyces proves the functional importance of these elements for $L 10$ binding. The identical elements of the mRNA and rRNA targets (ssA region and the C-G pair of dsA) suggest a complementary structural conservation in the regulatory protein. We reason that the -RNTLL- motif, which is the only one conserved among the 17 analyzed L1O protein sequences, is complementary to the conserved structural elements in dsA and ssA regions of the RNA target sites [9].

It may be noted in conclusion that the potential L1O mRNA target sites found in the two species of Streptomyces, $S$. griseus and $S$. coelicolor, prove once again the principle of feedback regulation of $r$-protein synthesis in prokaryotic organisms being based on the structural similarity of the m- and rRNA targets, competitive for binding of the regulatory proteins. Similarly to other prokaryotes, the mRNA target of L1O is located in Streptomyces in the untranslated rplJ leader region more than a 100 nucleotides upstream the $L 10$ start codon and therefore points to the important functional role of the rplJ leader. The conserved structure of the found potential L1O mRNA target is an evidence of its func. tional role for the autogenous control of expression of the $r p l J L$ genes in Streptomyces. The structural specificity of the LIO mRNA targets fo: und in Streptomyces might reflect the degree of phylogenetic remoteness. Given the peculiarities of the structural organization of the L1O target, as well as of the whole rplJ leader region (Paton and Zhyvoloup, in preparation), one might expect some other specific features pertinent to the molecular mechanism of the $L 10$-mediated autogenous control of the rplJL genes expression in Streptomyces.

\section{G. Б. Латон}

\section{ПОТЕНЦIИНІ МРНКОВ САИТИ-МIUЕНI ДЛЯ РИБОСОМНОГО БIЛКА L1O, GKI ВНЯВJEHO У STREPTOMYCES GRISEUS I S. COELICOLOR, ВКАЗУЮТЬ НА АУТОГЕННИИ КОНТРОЛЬ ЕКСПРЕСII ГЕНIВ TPIJL}

\section{P с з ко м}

Описано структурові особливості внявлекого у представників Streptomyces постійного сайта эв'язування рнбосомного білка $L I O$, якнй роэміпуеться в лідерній послідовності, що передує генам rolJL. Консервативиість структурової організації сайта у двох вндів Streptomyces і значна подібність структурн до $23 S$ мРНК свідчать про аутогенну регуляцію генів трIJL стрептоміцетів рибосоминм білхом LlO. 


\section{REFERENCES}

1. Lindaht $L$, Zengel J. $M$. Diverse mechanisms for regulating ribosomal protein synthesis in Escherichia coll // Progr. Nucl. Acids Res. and Mol. Biol.- 1993,- $\mathrm{N}$ 1.P. 3-57.

2. Christensen $T$, Johnsen $M$., Fiil $N$. $P$., Friesen $J$. D. RNA secondary structure and translational inhibition: anaiysis of the mutants in the rolf leader // EMBO J.1984.-3, N 7.-P. 1609-1612.

3. Paton E. B., Woodmaska M. I., Kroupskaya I. V. et al. Evidence for the ability of the L10 ribosomal proteins of Salmonella typhimurium and Kilebsiella pneumoniae to regulate $r p / / L$ genes expression in $E$, coll // FEBS Let. $1990-265, \mathrm{~N} 1,2 .-$ P. $129-132$.

4. Zhyvoloup A. N., Paton E. B. The E. coli ribosomal protein $L 10$ of $E$. coll is capable to regulate expression of the rplHL genes in Citrobacter freundii // Biopoly* mers and Cell. $-1993 .-9$, N 6.-P. 88-100.

5. Paton E. B., Zhyvoloup A. N., Woodmaska M. I., Kroupskaya I. V. Nucleotide sequence of the rplJL operon and the deduced primary structure of the encoded $L 1 O$ and $L 7 / L 12$, proteins of $S$. typhimurium compared to that of $E$. coli // Nucl. Acids Res.-1990.-18.-P. 4620.

6. Zhyvoloup A. N., Kroupskaya I. V., Lyaskovsky T. M., Paton E. B. Comparison of nucleotide sequences of the rplJ leader in Enterobacteria // Biopolymers and Cell.1994.-10, N 1.-P. 37-40.

7. Schmidt $J_{\text {., Bubenko }} M_{\text {., }}$ Subramanian A. A novel operon organization involving the genes for the chorismate synthase aromatic biosynthesis pathway and ribosomal GTPase center proteins $L 11, L I, L 10, L 12:$ rplKJL in Cyanobacterium synechocystis PCC 6803 // J. Biol. Chem.-1993.-268, N 36.-P. 27447-27457.

8. Liao $D$., Dennis $P . P$. The organization and expression of essential transcription translation component genes in the extremely thermophilic eubacterium Thermotoga maritima // Ibid.-1992.-267, N 32.-P. 22787-22797.

9. Tereschcenko $F, M$, Paton E. B. Identification of the conserved structural elements in the ribosomal protein $L 10$ which are essential for the autogenous regulation of gene expression in the rplJL operon of Enterabacteria // Biolopymers and Cell.1995.- 11, N 1.- P. 00-00.

10. Post $L$. E., Strycharz $C . D$, Nomura $M$, et at. Nucleotide sequence of the ribosomal protein cluster adjacent to the gene for RNA polymerase subunit $b$ in Escherichia coli // Proc. Nat. Acad. Sci. USA.- 1979.-76, N 4.-P. 1697-1701.

11. Climie $S$. C., Friesen J. D. In vivo and in vitro structural analysis of the rolJ mRNA leader in Escherichia coli // J. Biol. Chem.-1988.-263, N 29.-P. 16166-16175.

12. Egebjerg J., Douthwaite S. R., Liljas A., Garrett $R$. A. Characterization of the binding sites of protein $L I I$ and the $L 10$ (L12) pentameric complex in the GTPase domain of $23 \mathrm{~S}$ ribosomal RNA from Escherichia coli // J. Mol. Biol.-1990,-213, N 1.-P. $275-289$.

13. Kuester K, Kuberski S.,Piepersberg W. Distler J. Cloning and nucleotide sequence analysis of the nusg-rplK, rplA, rplJ, rplL gene cluster of $S$. griseus // EMBL accession N X72787.

14. Blanco G., Rodicio R., Puglia A. M. et al. Synthesis of ribosomal proteins during growth of Streptomyces coelicolor / EMBL accession N L24552.

15. Thompson J., Musters W., Cundliffe E., Dahlberg A. E. Replacement of the LII binding region within $E$. coli $23 \mathrm{~S}$ ribosomal RNA with its homologue from yeast: in vivo and in vitro analysis of hybrid ribosomes altered in the GTPase centre $/ /$ EMBO J.- 1993.- 12, N 4.- P. 1499-1504.

16. Draper $D$. E. How do proteins recognise specific RNA sites? New clews from autogenously regulated ribosomal proteins // Trends in Biochem. Sci.- 1989.-14, N 8.P. $335-338$.

17. Gutell $R$. R., Schnare M. N., Gray $M$. W. A compilation of large subunit (23S-like) ribosomal RNA sequences presented in a secondary structure format // Nucl. Acids Res.-1991.-18, Suppl.-P. 2319.

Inst. Cell. Biol. and Genet. Engineer.

15.09 .94

the Nat. Acad. Sci. of Ukraine, Kiev 